The Swiss National Science Foundation will supervise the scientific quality of the initiative, with help from international experts. This is a first for the granting agency, which has not previously been involved in the quality control of projects it does not fund itself.

\section{US politicians push for food-safety funding boost}

Twenty-three US senators are calling on President George W. Bush to boost funding for food-safety oversight in 2009. In a 6 December letter to Bush, the bipartisan group complained that the budget of the Food and Drug Administration (FDA) does not reflect its "critical" and growing role.

They noted, for instance, that the value of US agricultural imports had grown by $40 \%$ between 2003 and 2006, yet between 2004 and 2007, the number of employees dedicated to food safety at the FDA fell by $15 \%$ to 2,613. In February, Bush proposed increasing the agency's food-safety budget by $\$ 10.5$ million, to $\$ 467$ million. Congress has yet to approve the spending bill.

The letter comes on the heels of a highly critical report on 29 November from the FDA's scientific advisory board. It said that the \$1.9-billion agency cannot fulfil its mission because of the erosion and inadequacy of its scientific base and information-technology infrastucture.

\section{Private funds raise hopes for giant telescope}

Plans to build the world's largest optical telescope were jump-started with a 5 December announcement that a foundation set up by Intel co-founder Gordon Moore and his wife Betty had given the California Institute of Technology and the University of California \$200 million.

The two universities will also put in $\$ 100$ million for the billion-dollar project, called the Thirty Meter Telescope (TMT).

The gift puts the TMT ahead of two other planned mega-telescopes - the

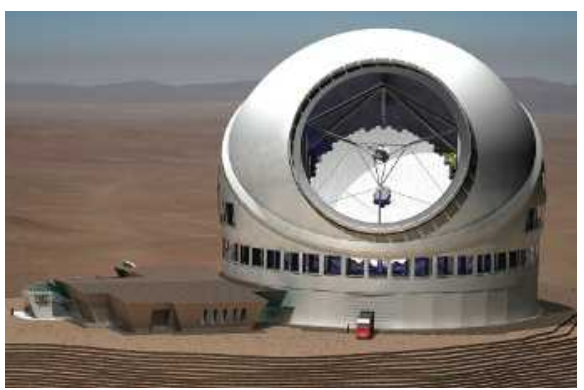

The Thirty Meter Telescope will have $\mathbf{4 9 2}$ mirrors.
Giant Magellan Telescope, a 24.5-metre telescope led by a consortium including the Carnegie Institution of Washington, and the Extremely Large Telescope, a 42-metre observatory planned by the European Southern Observatory. The TMT's 492 hexagonal mirrors will stretch for $\mathbf{3 0}$ metres, and the device is expected to achieve a better resolution than that of the Hubble Space Telescope. A final design is expected in 2009.

\section{Hackers steal personal data from US laboratories}

The Oak Ridge National Laboratory (ORNL) in Tennessee has warned some 12,000 people that their personal data may have been stolen as part of a "sophisticated cyber attack".

Hackers sent lab employees e-mails that seemed legitimate but contained attachments that, when opened, gave the hackers access to their computers. The 'phishing' scheme apparently allowed the hackers to download personal information about people visiting the laboratory between 1990 and 2004.

\section{Correction}

The legend to our graphic ' $\mathrm{CO}_{2}$ emissions 19902006' (Nature 447, 1038; 2007) erroneously gave $\mathrm{CO}_{2}$ intensity in tonnes per thousand US\$ GDP. It should have been tonnes per million US\$ GDP. 